Polymer Journal, Vol. 3, No. 3, pp 322-326 (1972)

\title{
Cooligomerization of Sulfur Dioxide with Octene-1
}

\author{
Junji Furukawa \\ Department of Synthetic Chemistry, Kyoto University, Kyoto, Japan. \\ Eiichi KoBayashi and Masaki HAYASHI* \\ Institute for Chemical Research, Kyoto University, Uji, Japan.
}

(Received August 2, 1971)

\begin{abstract}
The benzoyl peroxide initiated cooligomerization of sulfur dioxide with octene-1 in the presence of bromotrichloromethane was investigated. Alternating copolymers and oligomers having 1:1 composition with respect to sulfur dioxide and octene-1 were isolated from the reaction mixture. The oligomers were fractionated by thin-layer chromatography and the molecular weight, IR spectra and end group analyses of the fractions determined. It was found that the structure of the oligomers was mainly $\mathrm{C}_{6} \mathrm{H}_{5}-\left(-\mathrm{SO}_{2} \text {-octene-1- }\right)_{n}-\mathrm{Br}$. The oligomer seems to be formed by the reaction of phenyl radicals (originated from a fragment of benzoyl peroxide) and a monomer complex of sulfur dioxide and octene-1, not by the alternate addition of sulfur dioxide to the octene-1 radical or of octene- 1 to the sulfur dioxide radical.

KEY WORDS Cooligomerization / Sulfur Dioxide and Octene-1 / Thin Layer Chromatograph of Oligomer / IR Spectrum of Oligomer / End Group Analysis of Oligomer / Structure of Oligomer / $\mathrm{C}_{6} \mathrm{H}_{5}-\left(-\mathrm{SO}_{2} \text {-octene-1- }\right)_{n}-\mathrm{Br} /$ Oligomerization Mechanism / Alternating-Copolymerization Mechanism /
\end{abstract}

The copolymerization of sulfur dioxide with olefinic compounds is well known as one of the typical examples of alternating copolymerization. $^{1,2}$ However, the mechanism of the copolymerization of this type has not yet been completely established. In general there are two possibilities for the alternating copolymerization, one is the alternating addition of two monomers to the polymer-end radical and the other is the self propagation of the equimolar complex of both monomers. The latter mechanism is supported by UV-spectroscopic investigation of a mixture of sulfur dioxide and an electron donating monomer. ${ }^{3}$ The former one is discussed by Barb ${ }^{4}$ and Tokura, et al. ${ }^{5}$

One of the authors reported ${ }^{6}$ previously that the participation of the complex of sulfur dioxide with butene- 1 is responsible for the alternating copolymerization based on the terpolymerization results of sulfur dioxide, butene-1 and acrylonitrile. Recently, Matsuda, et al., proposed ${ }^{7}$

* Present address: Seitetsu Kagaku Co., Ltd., Kitahama, Higashi-ku, Osaka, Japan. that the copolymerization of sulfur dioxide with olefinic compounds seemed to proceed through the mechanism other than that via a chargetransfer complex of sulfur dioxide and olefinic compound.

In this report the low molecular weight polymers and oligomers of sulfur dioxide and octene-1 were prepared using a chain transfer agent, fractionated by TLC method, and subjected to the end-group analysis in order to elucidate the mechanism of alternating copolymerization.

\section{EXPERIMENTAL}

\section{Reagents}

Sulfur dioxide (anhydrous grade being 99.9\% at least) was obtained from Seitetsu Kagaku Co., Ltd. Before use, it was redistilled over anhydrous $\mathrm{CaSO}_{4}$ and purified by passing successively through the columns packed with $\mathrm{CaCl}_{2}$ and $\mathrm{P}_{2} \mathrm{O}_{5}$ followed by trapping at a Dry Icemethanol temperature.

Commercial octene-1 was used after distillation 
under a reduced pressure. Commercial bromotrichloromethane and $n$-heptane were purified by conventional methods. Benzoyl peroxide was used without purification.

\section{Oligomerization}

The standard recipe for oligometrization was as follows: $n$-heptane, $100 \mathrm{ml}$; octene-1, $5.6 \mathrm{~g}$ ( $50 \mathrm{mmol})$; benzoyl peroxide, $24.2 \mathrm{~g}(100 \mathrm{mmol})$; and bromotrichloromethane, $9.9 \mathrm{~g}(50 \mathrm{mmol})$. The reagents were placed in a glass test tube of $c a .200 \mathrm{~m} l$ under an atmosphere of dry nitrogen, the mixture was cooled to $-78^{\circ} \mathrm{C}$ and then $3.2 \mathrm{~g}$ of liquid sulfur dioxide $(50 \mathrm{mmol})$ introduced. The oligomerization was carried out in the sealed tube at $45^{\circ} \mathrm{C}$ for $72 \mathrm{hr}$ with occasional shaking. After a given time, the reaction mixture was washed with a dilute aqueous solution of sodium carbonate to remove benzoic acid and trace amount of benzenesulfonic acid. The reaction mixture was then successively distilled, fractionating into $n$-heptane, trace amounts of chloroform, benzene and bromobenzene fraction at $80^{\circ} \mathrm{C}(20 \mathrm{~mm})$, then trace amounts of $n$-heptyl bromide and hexachloroethane fraction at $80-$ $120^{\circ} \mathrm{C}(0.2 \mathrm{~mm})$.

Isolation and Analysis of the Reaction Products

Isolation and analysis of the reaction products were carried out by the following methods.

(1) The volatile products were qualitatively measured using a Yanaco GCG-550T gas-chromatograph equipped with 2-m long column packed with polyethylene glycol 6000 or dioctylphthalate at $140^{\circ} \mathrm{C}$ using $60 \mathrm{ml} / \mathrm{min}$ of $\mathrm{H}_{2}$ as a carrier gas. The retention time of the products was compared with those of authentic samples.

(2) The residues from the distillation were fractionated by thin-layer chromatography (TLC), and analysed. TLC analysis of oligomers was performed according to Inagaki, et al. ${ }^{8}$ One part of silica gel GF (Merk) was slurried with two parts of distilled water, and applied as the stationary phase onto a thick glass plate. The thickness of the layer was adjusted to 0.25 or $0.5 \mathrm{~mm}$. The gel layer was not activated. A ca. $5 \%$ of dimethyl sulfoxide solution of oligomers was placed on the starting line as a strip band using a micro-syringe. The plate was dried for several minutes and placed in a closed bath containing a developing solvent at room temperature. The first developing solvent was $50: 50$ mixture of benzene and chloroform, the second 60:40 mixture of chloroform and ethyl acetate and the third $40: 40: 20$ mixture of chloroform, ethyl acetate and acetone.

After the solvent front had risen $15 \mathrm{~cm}$ from the starting line, the plate was removed from the container and kept in an oven at ca. $80^{\circ} \mathrm{C}$ to prevent further ascent of the solvent front. The location of the spots was easily determined by their brown color. The located spots was scrapped off and subjected to solvent extraction with chloroform or dimethyl sulfoxide.

(3) The infrared spectrum (IR) of the oligomers fractionated by TLC was measured using a Hitachi EPI-S2 Infrared Spectrophotometer.

(4) The molecular weight of the oligomers was measured with a vapour pressure osmometer (Hewlett Packard-Model 302 VPO) at $37^{\circ} \mathrm{C}$ using chloroform solutions of the oligomers concentrations at from 0.2 to $2 \mathrm{wt} \%$.

(5) The composition of the oligomers was also evaluated from the elemental analysis of $\mathrm{C}, \mathrm{H}, \mathrm{O}, \mathrm{S}$, and $\mathrm{Br}$.

\section{RESULTS}

Reaction products containing both sulfur dioxide and octene-1 unit were evaluated by the above methods. $\mathrm{PhPh}, \mathrm{PhCOOPh},\left(\mathrm{PhSO}_{2}\right)_{2}$, and $\left(\mathrm{CCl}_{3}\right)_{2}$ were fractionated from the sample by the first TLC procedure. These products were identified by comparison of the IR spectra with authentic samples, but they were not analyzed quantitatively. The residue at the starting line

(1)

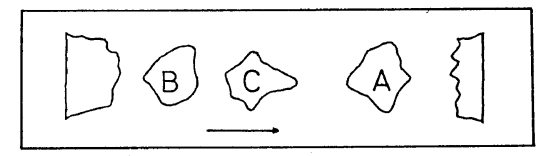

2nd. develop. using $\mathrm{CHCl}_{3}$-AcOEt

(2)

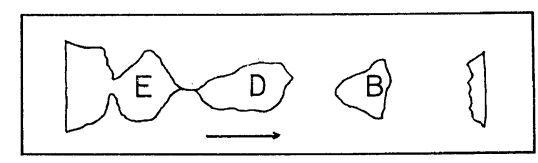

3rd. develop. using $\mathrm{CHCl}_{3}-\mathrm{AcOEt}-\mathrm{Acetone}$

Figure 1. TLC of oligomers obtained from $\mathrm{SO}_{2}$ and octene-1. 
Table I. Elemental analysis and molecular weight of the oligomers obtained by TLC

\begin{tabular}{|c|c|c|c|c|c|c|c|c|}
\hline $\begin{array}{l}\text { Number of } \\
\text { fraction }\end{array}$ & $\begin{array}{l}\text { Structure of } \\
\text { oligomer }\end{array}$ & & $\begin{array}{l}\mathrm{C}, \\
\%\end{array}$ & $\underset{\%}{\mathrm{H}}$ & $\begin{array}{l}\text { O } \\
\%\end{array}$ & $\begin{array}{l}\mathrm{S} \\
\%\end{array}$ & $\begin{array}{c}\mathrm{Br} \\
\%\end{array}$ & M.W. \\
\hline \multirow{2}{*}{ A } & \multirow{2}{*}{$\mathrm{Ph}\left(\mathrm{SO}_{2} \mathrm{M}\right) \mathrm{Br}$} & Found & 50.92 & 6.04 & 9.32 & 9.74 & 21.43 & 320 \\
\hline & & Calcd & 50.45 & 6.35 & 9.60 & 9.62 & 23.98 & 333 \\
\hline \multirow{2}{*}{ B } & \multirow{2}{*}{$\mathrm{Ph}\left(\mathrm{SO}_{2} \mathrm{M}\right)_{2} \mathrm{Br}$} & Found & 52.13 & 7.53 & 12.34 & 13.41 & 14.92 & 485 \\
\hline & & Calcd & 51.85 & 7.32 & 12.56 & 12.59 & 15.68 & 510 \\
\hline \multirow{2}{*}{$\mathrm{C}$} & \multirow{2}{*}{$\stackrel{\mathrm{O}}{\mathrm{O}}\left(\mathrm{SO}_{2} \mathrm{M}\right) \mathrm{OC} \mathrm{Ph}$} & Found & 66.04 & 6.83 & 16.38 & 8.91 & 0.28 & 390 \\
\hline & & Calcd & 67.35 & 7.00 & 17.09 & 8.56 & 0 & 375 \\
\hline \multirow{2}{*}{ D } & \multirow{2}{*}{$\mathrm{Ph}\left(\mathrm{SO}_{2} \mathrm{M}\right)_{3} \mathrm{Br}$} & Found & 53.40 & 8.02 & 14.32 & 13.75 & 9.84 & 710 \\
\hline & & Calcd & 52.54 & 7.79 & 14.00 & 14.02 & 11.64 & 686 \\
\hline $\mathrm{E}$ & & Found & 50.42 & 6.58 & 15.12 & 9.02 & 7.42 & 1120 \\
\hline
\end{tabular}

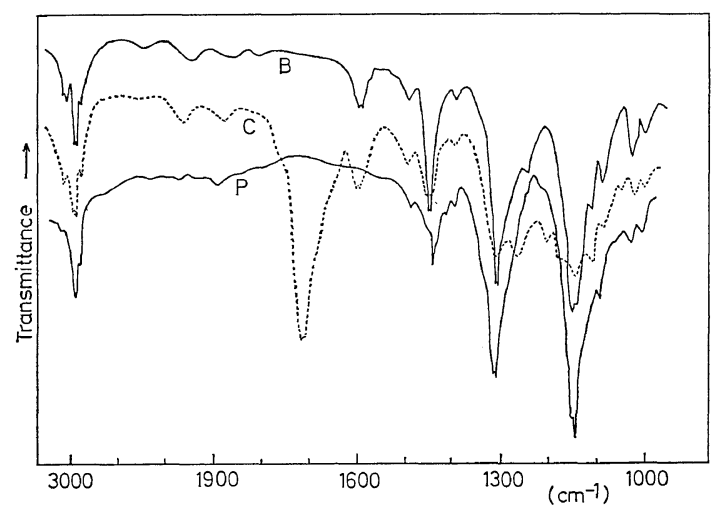

Figure 2. IR spectra of oligomers and polysulfone obtained from $\mathrm{SO}_{2}$ 'and octene-1: $\mathrm{B}, \mathrm{Ph}-\left(-\mathrm{SO}_{2}-\right.$ octene-1- $)_{2}-\mathrm{Br} ; \mathrm{C}$, $\mathrm{Ph}-\left(-\mathrm{SO}_{2}-\right.$ octene-1-)-OOCPh; P, Polysulfone.

was scrapped off and subjected to solvent extraction with chloroform or dimethyl sulfoxide. This residue was again developed as shown in Figure 1(1). From the residue of the second development, the fractions $B, D$ and $E$ were separated by a third development as shown in Figure 1(2). The fractions A, B, C, D, and E were scrapped off and subjected to solvent extraction with chloroform or dimethyl sulfoxide and then analysed.

The yield of each fraction was approximately in the order of $\mathrm{E}>\mathrm{B}>\mathrm{D}>\mathrm{A}>\mathrm{C}$. The total amount of the fraction $(\mathrm{A}-\mathrm{E})$ was $c a .3 \mathrm{~g}$ and the residual ca. $6 \mathrm{~g}$.

The results of the elemental analysis, molecular weight determinations and IR spectra of the fractions are shown in Table I and Figure 2. The IR spectra of $\mathrm{A}, \mathrm{B}$, and $\mathrm{D}$ are similar and show strong absorptions at 1310 and $1140 \mathrm{~cm}^{-1}$ assignable to $\nu_{\mathrm{as}}(\mathrm{S}=\mathrm{O})$ and $\nu_{\mathrm{s}}(\mathrm{S}=\mathrm{O})$ respectively, and at 3100-3000, 1600-1580, and $2000-1650 \mathrm{~cm}^{-1}$ assignable to phenyl group. In the region of $2960-2850 \mathrm{~cm}^{-1}$ and 1450 $1380 \mathrm{~cm}^{-1}$ the absorption bands arise from $\mathrm{CH}_{3}$, $\mathrm{CH}_{2}$, and $\mathrm{CH}$. The IR spectrum of $\mathrm{C}$ shows absorption at $c a$. 1710 and $1280-1160 \mathrm{~cm}^{-1}$ assignable to carbonyl group. The fraction $\mathrm{E}$ seems to be a mixture of units containing the fractions $A, B, C$, and $D$.

There is no $-\mathrm{SO}_{2} \mathrm{Br}$ end group in the fractions $\mathrm{A}, \mathrm{B}, \mathrm{C}, \mathrm{D}$, and $\mathrm{E}$, because no fraction reacted with ethanolic silver nitrate solution at below $-10^{\circ} \mathrm{C}$ in the reaction described by Khodair. ${ }^{9}$ From these results, the structures of oligomers A, B, C, and D are proposed as shown in Table $\mathrm{I}$, respectively.

\section{DISCUSSION}

The tendency to alternation has been interpreted in different ways by many authors. Bartlett, et al. ${ }^{10}$ proposed the formation of a 1:1 monomer complex followed by polymerization of the complex to give alternating copolymers. Price ${ }^{11}$ ascribed the alternating tendency to the polar interactions between the growing polymer radicals and monomers, whereas Walling, et al., ${ }^{12}$ proposed a mechanism involving a complex formation between the polymer radical and the monomer. 
The products of the copolymerization of styrene and sulfur dioxide are not always of $1: 1$ composition, although the kinetic data fit the copolymerization of styrene and the CTcomplex of styrene-sulfur dioxide. ${ }^{4,13}$ The $1: 1$ complex formation was confirmed in styrenesulfur dioxide, ${ }^{4}$ olefin-sulfur dioxide ${ }^{3}$ by UVspectroscopy. Consequently, the reaction mechanism is uncertain.

In this section, the authors discuss the mechanism of the alternating cooligomerization as well as the alternating copolymerization of sulfur dioxide with octene-1. The oligosulfone prepared in this work always had a $1: 1$ composition of sulfur dioxide to octene-1 unit. On the other hand, Kharasch obtained ${ }^{14}$ an oligomer of $\mathrm{Cl}_{3} \mathrm{C}-\mathrm{M}-\mathrm{SO}_{2}-\mathrm{M}-\mathrm{Br}$ type by the reaction of sulfur dioxide with octene-1 $(\mathrm{M})$. in the presence of bromotrichloromethane under UV-irradiation. The disagreement between Kharasch's results and ours may due to the difference in the initiation reaction. The main reaction scheme of cooligomerization seems to be as follows:

$$
\mathrm{Ph} \cdot \stackrel{\mathrm{SO}_{2} \cdot \mathrm{M}}{\longrightarrow} \mathrm{Ph}-\mathrm{SO}_{2}-\mathrm{M} \cdot \stackrel{\mathrm{SO}_{2} \cdot \mathrm{M}}{\longrightarrow} \mathrm{Ph}-\mathrm{SO}_{2}-\mathrm{M}-\mathrm{SO}_{2} \mathrm{M} .
$$

$$
\begin{aligned}
& \mathrm{PhCOO} \cdot \stackrel{\mathrm{SO}_{2} \cdot \mathrm{M}}{\longrightarrow} \mathrm{PhCOO}-\mathrm{SO}_{2}-\mathrm{M} \cdot \stackrel{\mathrm{SO}_{2} \cdot \mathrm{M}}{\longrightarrow} \\
& \mathrm{PhCOO}-\mathrm{SO}_{2}-\mathrm{M}-\mathrm{SO}_{2}-\mathrm{M} \text {. } \\
& \mathrm{Ph} \cdot \stackrel{\mathrm{SO}_{2}}{\longrightarrow} \mathrm{Ph}-\mathrm{SO}_{2} \cdot \stackrel{\mathrm{M}}{\longrightarrow} \mathrm{PhSO}_{2}-\mathrm{M} \cdot \stackrel{\mathrm{M}}{\longrightarrow} \\
& \mathrm{PhSO}_{2}-\mathrm{M}-\mathrm{M} \text {. }
\end{aligned}
$$

Tokura, et al., reported ${ }^{15}$ that the phenyl radical can attack sulfur dioxide, whereas the $\pi$-type radica ${ }^{16}$ does not. The oligomers of $\mathrm{A}, \mathrm{B}, \mathrm{C}$, and $\mathrm{D}$ shown in Table $\mathrm{I}$ are obtainable through the course of $1-3$. If the reaction follows the route 3, products such as $\mathrm{Ph}-\mathrm{SO}_{2}-\mathrm{Br}, \mathrm{Ph}-\mathrm{SO}_{2}-$ $\mathrm{M}-\mathrm{M}-\mathrm{Br}, \quad \mathrm{Ph}-\mathrm{SO}_{2}-\mathrm{OOCPh}$ or $\mathrm{Ph}-\mathrm{SO}_{2}-\mathrm{M}-\mathrm{M}-$ OOCPh together with $\mathrm{Ph}-\left(\mathrm{SO}_{2}-\mathrm{M}\right)_{n}-\mathrm{Br}$ or $\mathrm{Ph}-$ $\left(\mathrm{SO}_{2}-\mathrm{M}\right)_{n}-\mathrm{OOCPh}$ should be detected. However, these products were not obtained. This result suggests that the oligomerization reaction proceeds via the course of 1 and 2 , and that the sulfur dioxide and octene-1 cooligomerize by reaction between a growing radical and a monomer complex of sulfur dioxide and octene-1.

The oligomer containing PhCOO group was only obtained in fraction $\mathrm{C}$. This suggests that the initiation is by phenyl radicals, and if so, the initiating radical attacks the complex of sulfur dioxide and octene- 1 from the side of sulfur dioxide. The problem in head-to-tail structures of polysulfone has already been discussed by Kharasch ${ }^{14}$ and Marvel. ${ }^{17}$ The oligosulfone may give further information about this problem and be discussed in a subsequent report.

Fractionation of the products showed that the detectable oligomers were mainly $\mathrm{Ph}-\left(\mathrm{SO}_{2}-\mathbf{M}\right)_{n}-$ $\mathrm{X}$, although sulfur dioxide, octene- 1 and the complex were reactive monomers in the system, suggesting that the reactivity of the complex of sulfur dioxide and octene- 1 is greater than that of octene-1 and sulfur dioxide.

\section{REFERENCES}

1. D.S. Friderick, H.D. Cogan, and C.S. Marvel, J. Amer. Chem. Soc., 56, 1815 (1934); C. S. Marvel and E. D. Weil, ibid., 76, 61 (1954).

2. F. S. Dainton and K. J. Ivin, Proc. Roy. Soc., A212, 96 (1952); N. L. Zutty, C. W. Wilson, G. H. Potter, D. C. Priest, and C. J. Witworth, J. Polymer Sci., Part A, 3, 2781 (1965).

3. H. Dey and H. König, Z. Phys. Chem., 41 B, 365 (1938); D. Booth, F. S. Dainton, and K. J. Ivin, Trans. Faraday Soc., 55, 1293 (1959).

4. W. G. Barb, Proc. Roy. Soc., A212, 66, 177 (1952).

5. N. Tokura and M. Matsuda, Kogyo Kagaku Zasshi (J. Chem. Soc. Japan, Ind. Chem. Sect.), 64, 501 (1961).

6. K. Ito, H. Hayashi, T. Saegusa, and J. Furukawa, Kogyo Kagaku Zasshi (J. Chem. Soc. Japan, Ind. Chem. Sect), 65, 703, 1634, and 1878 (1962).

7. M. Matsuda, M. Iino, S. Numata, and K. Seki, Preprint, Symposium on Charge-Transfer Complex, Osaka, 1970, p 43.

8. H. Inagaki, H. Masuda, and F. Kamiyama, Macromolecules, 1, 520 (1968).

9. A. I. Khodair and B. S. Thyagarajan, "Mechanism of Reaction of Sulfur Compounds," Vol. 1, Interscience Research Foundation, Calif., 1967, p 1966.

10. P. D. Bartlett and K. Nozaki, J. Amer. Chem. Soc., 68, 1495 (1946).

11. C. C. Price, J. Polym. Sci., 1, 83 (1946); 3, 772 (1948); J. Alfrey and C. C. Price, ibid., 2, 101 (1947). 
12. C. Walling, E.R. Briggs, K. B. Wolfstirn, and F. R. Mayo, J. Amer. Chem. Soc., 70, 1537 (1948); C. Walling, D. Seymour, and K. B. Wolfstirn, ibid., 70, 1544 (1948).

13. W. G. Barb, J. Polym. Sci., 10, 49 (1953).

14. M. S. Kharasch and H. N. Friedlander, J. Org. Chem., 13, 882 (1948).
15. H. Takeuchi, T. Nagai, and N. Tokura, Tetrahedron, 23, 1783 (1967).

16. H. Takeuchi, T. Nagai, and T. Tokura, Bull. Chem. Soc. Japan, 40, 2375 (1967).

17. C.S. Marvel and E. D. Weil, J. Amer. Chem. Soc., 75, 2326 (1953). 